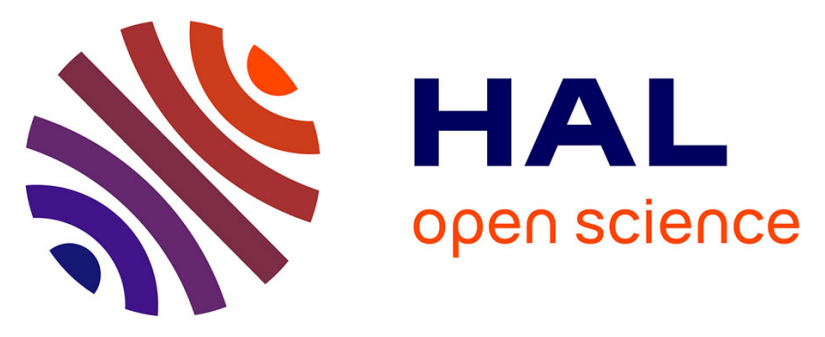

\title{
Ruthenium(II) complexes based on tridentate polypyridine ligands that feature long-lived room-temperature luminescence
}

Giulio Ragazzon, Peter Verwilst, Sergey A. Denisov, Alberto Credi, Gediminas Jonusauskas, Nathan D. Mcclenaghan

\section{To cite this version:}

Giulio Ragazzon, Peter Verwilst, Sergey A. Denisov, Alberto Credi, Gediminas Jonusauskas, et al.. Ruthenium(II) complexes based on tridentate polypyridine ligands that feature longlived room-temperature luminescence. Chemical Communications, 2013, 49 (80), pp.9110-9112. 10.1039/C3CC45387A . hal-00874436

\section{HAL Id: hal-00874436 https://hal.science/hal-00874436}

Submitted on 8 Mar 2018

HAL is a multi-disciplinary open access archive for the deposit and dissemination of scientific research documents, whether they are published or not. The documents may come from teaching and research institutions in France or abroad, or from public or private research centers.
L'archive ouverte pluridisciplinaire HAL, est destinée au dépôt et à la diffusion de documents scientifiques de niveau recherche, publiés ou non, émanant des établissements d'enseignement et de recherche français ou étrangers, des laboratoires publics ou privés.

\section{(1)(1) 8 (2)}

Distributed under a Creative Commons Attribution - NonCommercial - ShareAlikel 4.0 


\title{
Ruthenium(II) complexes based on tridentate polypyridine ligands that feature long-lived room-temperature luminescence
}

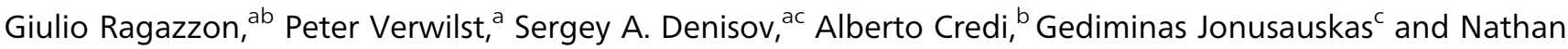 \\ D. McClenaghan*a
}

Integrating a matched organic chromophore and a Ru(II) complex with optimized tridentate polypyridine ligands instils reversible electronic energy transfer giving an unusually long room temperature luminescence lifetime ( $42 \mu \mathrm{s})$ without compromising the emission quantum yield.

Transition metal polypyridine complexes in general, and ruthenium complexes and dyads in particular, have been widely studied to better understand and harness their visible absorption, redox and photochemical processes. ${ }^{1}$ This is typically with a view to application in the general areas of photosensitizers, dyes, sensors, LEDs, catalysts as well as nanotechnology. ${ }^{2}$ Ligand modification is central in determining many of the key excited-state properties of the complexes, and hence emission (namely efficiency and luminescence decay rates). Polypyridine ligands generally bind in a bidentate or tridentate fashion, offering complexes with different coordination geometries and properties. Indeed, tridentate ligands can offer access to complexes with 1D-linear geometries (molecular rods and wires), but the luminescence properties are typically extensively hampered by thermally accessible metal-centred states which serve to diminish luminescence. ${ }^{1}$ As an illustration, while $\left[\mathrm{Ru}(\mathrm{bpy})_{3}\right]^{2+}$ (bpy $=2,2^{\prime}$-bipyridine) has a quantum yield $\left(\Phi_{\mathrm{em}}\right)$ of 0.059 and a luminescence lifetime of $890 \mathrm{~ns}$ in degassed acetonitrile, the terpyridine analogue $\left[\mathrm{Ru}(\mathrm{tpy})_{2}\right]^{2+}$ (tpy $=2,2^{\prime} ; 6^{\prime}, 2^{\prime \prime}$-terpyridine) has much lower corresponding values of $<10^{-5}$ and $0.25 \mathrm{~ns}^{3}$

Strategies to improve these parameters have reposed on defavouring thermally-activated loss by increasing the energy gap between states on lowering emissive ${ }^{3}$ MLCT levels, as a result of incorporating highly electron poor tpy-like ligands. ${ }^{4}$ Additionally, coupling with an organic auxiliary led to luminescence

\footnotetext{
${ }^{a}$ Univ. Bordeaux/CNRS, ISM, 351 cours de la Libération, 33405 Talence cedex, France. E mail: n.mc clenaghan@ism.u bordeaux1.fr; Fax: +33 (0)540006158; Tel: +33 (0)540003321

${ }^{b}$ Dipartimento di Chimica "G. Ciamician", Università di Bologna, and Interuniversity Center for the Chemical Conversion of Solar Energy, via Selmi 2, 40126 Bologna, Italy. E mail: alberto.credi@unibo.it

${ }^{c}$ Univ. Bordeaux/CNRS, LOMA, 351 cours de la Libération, 33405 Talence cedex, France.E mail: g.jonusauskas@loma.u bordeaux1.fr
}

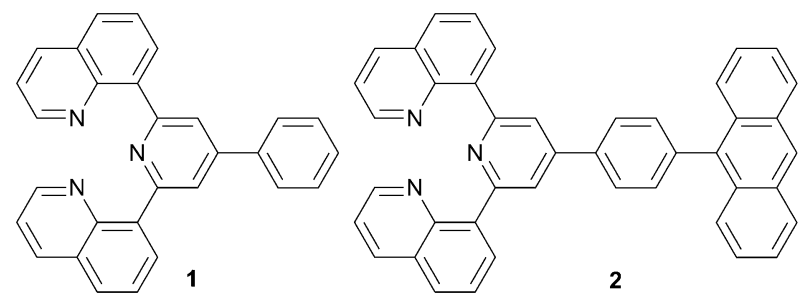

Fig. 1 Anthracene free (1) and appended (2) tridentate ligands employed in forming complexes $\left[\mathrm{Ru}(1)_{2}\right]^{2+}$ and $\left[\mathrm{Ru}(2)_{2}\right]^{2+}$.

lifetimes as long as $1.8 \mu \mathrm{s}$ albeit with a small quantum yield of $10^{-4.5}$ In two different approaches, microsecond luminescence lifetimes were recently obtained using heteroleptic ruthenium complexes based on tridentate ligands which comprise carbenes, ${ }^{6}$ or replacing the two external pyridine moieties of tpy with quinolines, giving emissive tridentate ligand-based octahedral ruthenium complexes. ${ }^{7}$

Herein we report a straightforward structural modification of the latter type of complex ( $c f$. model complex $\left[\mathrm{Ru}(\mathbf{1})_{2}\right]^{2+}$, Fig. 1), involving the judicious integration of an auxiliary chromophore with matched properties (vide infra), with the goal of giving access to a much longer-lived luminescent complex, while retaining a similar emission quantum yield. This modification could broaden the scope of functions in multicomponent artificial arrays by changing excited-state properties, including lifetime.

The auxiliary chromophore was anticipated to exert the desired role if the newly-introduced triplet level has a slow inherent deexcitation and is quasi-isoenergetic with the emissive MLCT state. This would permit reversible intercomponent excited-state energy transfer with the organic subunit acting as an energy reservoir and emission emanating from the metallic sub-unit with a net luminescence lifetime increase. ${ }^{8}$ Anthracene was anticipated to be an appropriate candidate (triplet energy at $1.8 \mathrm{eV}$; $\tau_{\text {phos }}=3300 \mu \mathrm{s}$ ), whose incorporation gave the prototype $\left[\mathrm{Ru}(2)_{2}\right]^{2+}$, see Fig $1 .{ }^{3}$ Equally, this would add to the rather limited number of matched chromophore pairs. ${ }^{8}$

Model ligands 1 and 2 (Fig. 1) were both prepared from a common intermediate, 4-(4-bromophenyl)-2,6-di(quinolin-8-yl)pyridine (see the ESI $\dagger$ for detailed procedures). ${ }^{9}$ Ligand 1 was prepared by a palladium-catalysed hydro-dehalogenation. ${ }^{10}$ 
Molecule 2 was prepared through a Suzuki coupling reaction with the pinacol ester of 9-anthryl boronic acid, with a yield of $34 \%$. Complex formation was achieved upon reacting 1 or 2 with $\mathrm{Ru}(\mathrm{DMSO})_{4} \mathrm{Cl}_{2}$ in hot ethylene glycol under microwave irradiation, yielding the desired complexes $\left[\mathrm{Ru}(\mathbf{1})_{2}\right]^{2+}$ and $\left[\mathrm{Ru}(2)_{2}\right]^{2+}$, respectively.

While three distinct stereoisomers are possible (mer; cis, fac and trans, fac), the thermodynamically favourable mer-form can be formed predominantly upon heating at $200{ }^{\circ} \mathrm{C} .{ }^{11}$ Anion metathesis reactions and column chromatography afforded the pure complexes as hexafluorophosphate salts.

Electronic absorption spectra (see ESI $\dagger$ ) are dominated by ligandbased absorption bands in the UV region and similar MLCT absorption in the visible region for both $\left[\mathrm{Ru}(\mathbf{1})_{2}\right]^{2+}$ and $\left[\mathrm{Ru}(2)_{2}\right]^{2+}$. An additional anthracene absorption band is also observed, which retains its vibronic fine structure implying only weak ground-state coupling between the adjacent chromophores, suggesting an approach to orthogonality of the $\pi$-systems, as a result of steric constraints including peri-proton interactions. Consequently, each chromophore is anticipated to retain its own specific properties in the ensemble.

Steady-state luminescence shows red MLCT-based emission for both $\left[\operatorname{Ru}(1)_{2}\right]^{2+}$ and $\left[\operatorname{Ru}(2)_{2}\right]^{2+}\left(\lambda_{\text {em max }}=686 \mathrm{~nm}\right)$ with similar emission quantum yields in degassed acetonitrile $\left(\Phi_{\mathrm{em}}=0.013\right)$, see ESI. $\uparrow$ However, a more pronounced oxygen sensitivity is observed in $\left[\mathrm{Ru}(2)_{2}\right]^{2+}$ vs. $\left[\operatorname{Ru}(\mathbf{1})_{2}\right]^{2+}$ (Table 1$)$. While the latter molecule shows a low $\Phi_{\text {em deoxy }} / \Phi_{\text {em oxy }}$ ratio of 5.8 , in contrast, a much higher value of 33 is obtained with $\left[\mathrm{Ru}(2)_{2}\right]^{2+}$, which is consistent with a much longer excited-state lifetime.

Time-resolved spectroscopies in the sub-picosecond to microsecond regimes give supplementary information on the nature of the excited molecule and excited-state processes in the multicomponent species. An emission lifetime of $2.7 \mu$ s was obtained for degassed $\left[\mathrm{Ru}(\mathbf{1})_{2}\right]^{2+}$, which is similar to the previously reported tolyl analogue. ${ }^{11}$ However, a luminescence lifetime which is over an order of magnitude longer ( $35 \mu \mathrm{s})$ was measured for a micromolar solution of $\left[\mathrm{Ru}(2)_{2}\right]^{2+}$, see Fig. 2, which is conducive to enhanced oxygen sensitivity. Extrapolating to infinite dilution gave an apparent deexcitation rate of $23800 \mathrm{~s}^{-1}$ or lifetime of $42 \mu \mathrm{s}$, much longer than the unelaborated chromophore (see Fig. S5, ESI $\dagger$ ).

While emission data give information on the ultimate fate of the excited molecule, transient absorption spectroscopy elucidates the management of energy by the excited molecule and origin of the large lifetime enhancement. Excitation of $\left[\mathrm{Ru}(2)_{2}\right]^{2+}$, either into the MLCT absorption band at $465 \mathrm{~nm}$ or predominantly in the anthracene-centred band at $355 \mathrm{~nm}$ rapidly led to the population of the anthracene triplet, denoted by a characteristic $\mathrm{T}_{n} \leftarrow \mathrm{T}_{1}$ absorption at $430 \mathrm{~nm}$, see Fig. 3. The kinetics of deexcitation of this organic triplet

Table 1 Photophysical properties of ruthenium complexes $\left[R u(1)_{2}\right]^{2+}$ and $\left[\mathrm{Ru}(2)_{2}\right]^{2+}$ in acetonitrile at room temperature

\begin{tabular}{llllll} 
& $\begin{array}{l}\lambda_{\text {em max. }}{ }^{a} \\
(\mathrm{~nm})\end{array}$ & $\Phi_{\text {em oxy }}{ }^{b}$ & $\Phi_{\text {em deoxy }}{ }^{c} \tau^{d}(\mu \mathrm{s})$ & $K_{\text {eq }}$ \\
\hline$\left[\operatorname{Ru}(1)_{2}\right]^{2+}$ & 686 & $2.2 \times 10^{3}$ & 0.013 & 2.7 & \\
{$\left[\mathrm{Ru}(2)_{2}\right]^{2+}$} & 686 & $4 \times 10^{4}$ & 0.013 & $75 \times 10^{6 e} ; 42$ & $15.2 \pm 2^{e, f}$
\end{tabular}

${ }^{a}$ Recorded on streak camera and uncorrected. ${ }^{b}$ Luminescence quan tum yield in air equilibrated $\mathrm{CH}_{3} \mathrm{CN}$ solution $c f$. $\left[\mathrm{Ru}(\mathrm{bpy})_{3}\right]^{2+} \cdot{ }^{3}{ }^{c}$ Idem in degassed $\mathrm{CH}_{3} \mathrm{CN}$ solution. ${ }^{d}$ Luminescence lifetime of ${ }^{3}$ MLCT in dilute degassed $\mathrm{CH}_{3} \mathrm{CN} .{ }^{e}$ Determined via transient absorption spectroscopy in degassed $\mathrm{CH}_{3}$ CN. ${ }^{f}$ Excited state equilibrium constant (see ESI).

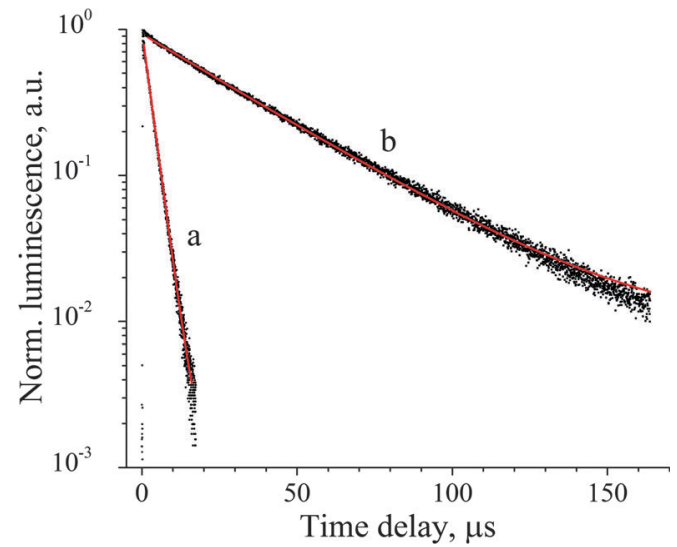

Fig. 2 Luminescence decay of dilute $\left[R u(1)_{2}\right]^{2+}(a)$ and anthracene appended $\left[\mathrm{Ru}(2)_{2}\right]^{2+}(\mathrm{b})$ in acetonitrile at $700 \mathrm{~nm}\left(\lambda_{\text {exc }}=465 \mathrm{~nm}\right)$.

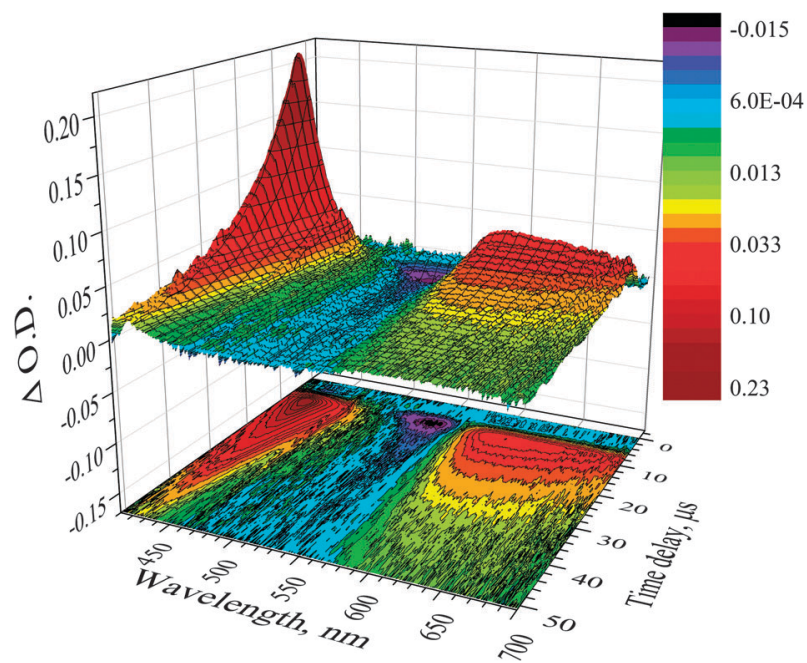

Fig. 3 Transient absorption map of $\left[R u(2)_{2}\right]^{2+}$ showing deexcitation of the equilibrated bichromophoric molecule in acetonitrile $\left(\lambda_{\text {exc }}=465 \mathrm{~nm}\right)$.

band mirrors those of the red emission (see ESI $\dagger$ ). This behaviour is attributed to a dynamic excited-state equilibrium involving the two chromophores confirming that excited states on the adjacent chromophores may be considered quasi-isoenergetic, thus permitting rapid and reversible electronic energy transfer (REET). As a similar quantum yield was obtained for both $\left[\operatorname{Ru}(\mathbf{1})_{2}\right]^{2+}$ and $\left[\mathrm{Ru}(2)_{2}\right]^{2+}$, this implies the energy shuttling in $\left[\mathrm{Ru}(2)_{2}\right]^{2+}$ is essentially quantitative.

To gain further insight into the energies of the pertinent states, low temperature phosphorescence measurements were undertaken with both $\left[\operatorname{Ru}(\mathbf{1})_{2}\right]^{2+}$ and $\left[\operatorname{Ru}(2)_{2}\right]^{2+}$. At $77 \mathrm{~K}$, slightly blue-shifted MLCT emission $\left(\lambda_{\mathrm{em} \max }=672 \mathrm{~nm}\right)$ could be observed from $\left[\mathrm{Ru}(\mathbf{1})_{2}\right]^{2+}$ with respect to room temperature, while in the bichromophoric complex the emission of $\left[\operatorname{Ru}(2)_{2}\right]^{2+}$ was located further to the red $\left(\lambda_{\mathrm{em} \max }=\right.$ $712 \mathrm{~nm}$ ) and attributed to a slightly lower-lying anthracene emission, with only a small energy difference between high energy emission features. While such a small value cannot be measured directly without significant error, kinetic analysis (see ESI + ) allows determination of the energy gap at $430 \mathrm{~cm}^{-1}$, which is consistent with reversible interchromophore electronic energy transfer at room temperature.

The establishment of a dynamic excited-state equilibrium from the non-equilibrated initial excited state can be observed in real-time 


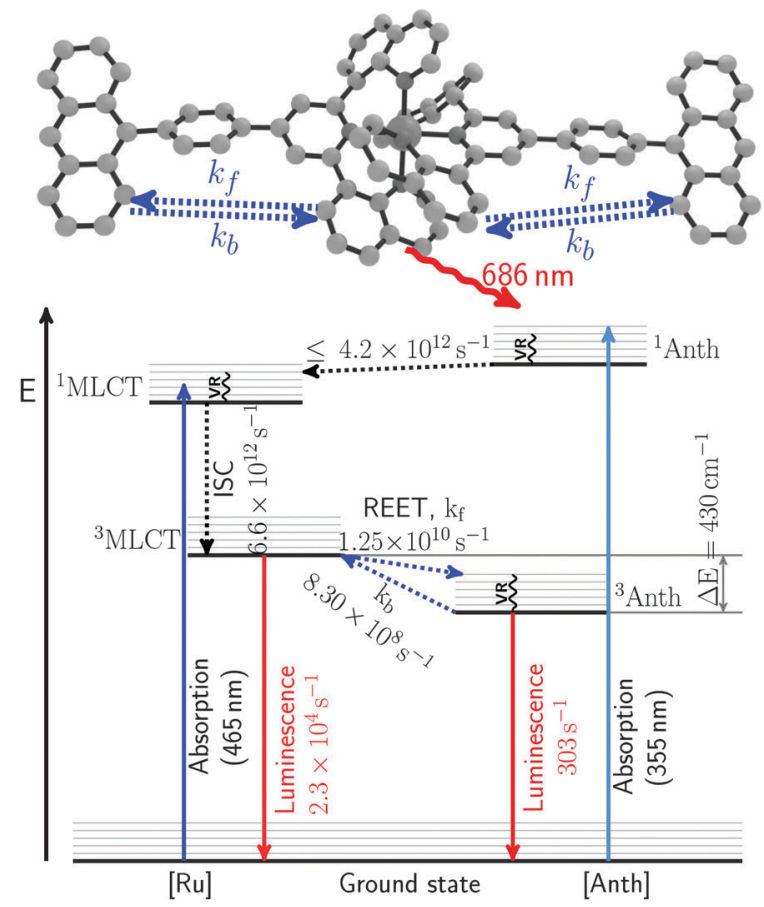

Fig. 4 Jablonski diagram showing pertinent energy levels and kinetics of reversible electronic energy transfer (REET) and delayed luminescence. ISC = intersystem crossing; $\mathrm{VR}=$ vibrational relaxation.

by picosecond transient absorption spectroscopy. Indeed, the rise time of the anthracene triplet absorption signature (see ESI $\dagger$ ) is measured to be $75 \mathrm{ps}$. This value gives the rate of establishment of equilibrium $\left(k=13.5 \times 10^{9} \mathrm{~s}^{-1}\right)$, and is equal to the sum of forward $\left(k_{\mathrm{f}}\right)$ and backward $\left(k_{\mathrm{b}}\right)$ energy transfer processes. ${ }^{8}$ The relative $k_{\mathrm{f}}$ and $k_{\mathrm{b}}$ values can be determined by direct observation based on transient absorption signatures, while the excited-state equilibrium constant $\left(K_{\text {eq }}\right)$, is a ratio of $k_{\mathrm{f}}$ to $k_{\mathrm{b}}$. This can also be indirectly estimated using inherent deexcitation and lifetime decay data (see ESI $\dagger$ ). Concerning direct observation, changes in absorption of the MLCT band at $485 \mathrm{~nm}$ (Fig. S7, ESI $\dagger$ ) denote the relative populations immediately after excitation, as well as the subsequent metastable equilibrated system. This then allows determination of the equilibrated population to be largely (94\%) in favour of the organic chromophore, and equilibrium constant $K_{\mathrm{eq}}$ at $15.2 \pm 2$. This value agrees well with that estimated at $14.8 \mathrm{via}$ the aforementioned luminescent decay method. Consequently $k_{\mathrm{f}}$ and $k_{\mathrm{b}}$ were determined at $1.25 \times 10^{10} \mathrm{~s}^{-1}$ and $8.30 \times 10^{8} \mathrm{~s}^{-1}$, respectively, see Fig. 4 and ESI. $\dagger$

Ultrafast processes of intersystem crossing and formal singletsinglet energy transfer were estimated using femtosecond transient absorption spectroscopy, upon exciting the MLCT absorption band or predominantly into the anthracene absorption band, respectively. Based on rapid changes in the spectrum at around $600 \mathrm{~nm}$ following visible excitation $\left(\lambda_{\text {exc }}=490 \mathrm{~nm}\right)$ the ${ }^{1}$ MLCT to ${ }^{3}$ MLCT intersystem crossing was observed to occur with a time constant of $150 \mathrm{fs}$ (Fig. S9, ESI $\dagger$ ). Meanwhile, on exciting anthracene at $370 \mathrm{~nm}$ and observing changes in the visible ground-state MLCT absorption band at $530 \mathrm{~nm}$ (Fig. S10, ESI $\dagger$ ), an upper limit could be estimated for the electronic energy transfer rate from an excited singlet anthracene to lower-lying ${ }^{1}$ MLCT level at around $4.2 \times 10^{12} \mathrm{~s}^{-1}$. Indeed, a small amount of direct MLCT excitation and cooling would effectively change the apparent rate to some extent, while remaining on the same order of magnitude. The ensemble of excited-state processes and rates describing energy transfer, energy distribution at equilibrium and subsequent emission are given in Fig. 4.

To summarise, reversible electronic energy transfer and an optimised coordination geometry conspire to give a tridentate ruthenium complex with an unprecedented luminescence lifetime, without compromising the luminescence efficiency. Time-resolved spectroscopies showed that due to reversible intercomponent electronic energy transfer, excited-state equilibration is reached in less than 400 picoseconds with an average of $94 \%$ of energy being stocked on the organic energy reservoir in the equilibrated system and that subsequent emission occurs on the microsecond timescale $\left(\tau_{\mathrm{em}}=42 \mu \mathrm{s}\right)$ from the metal-centre. Interestingly, this energy-shuttling was instilled in a predetermined fashion based on a rudimentary knowledge of energies of excited-states and intrinsic deexcitation rates in respective molecular sub-units. As well as offering the possibility of more efficient photosensitizers and improving underperforming chromophores, these REET processes are of potential interest in moleculebased machines, detection and light-emitting devices.

The authors wish to acknowledge financial support from the CNRS, Université Bordeaux I, Région Aquitaine and Collegio Superiore dell'Università di Bologna.

\section{Notes and references}

1 S. Campagna, F. Puntoriero, F. Nastasi, G. Bergamini and V. Balzani, in Top. Curr. Chem., Springer, Berlin, 2007, vol. 280, p. 117.

2 (a) N. Armaroli and V. Balzani, Energy for a Sustainable World, Wiley VCH Verlag GmbH \& Co. KGaA, 2010; (b) M. Gratzel, Acc. Chem. Res., 2009, 42, 1788 1798; (c) H. Imahori, Y. Mori and Y. Matano, J. Photochem. Photobiol., C, 2003, 4, 51 83; (d) V. Balzani, A. Credi and M. Venturi, Molecular Devices and Machines: Concepts and Perspectives for the Nanoworld, Wiley, 2nd edn, 2008.

3 M. Montalti, A. Credi, L. Prodi and M. T. Gandolfi, Handbook of Photochemistry, CRC/Taylor \& Francis London, 3rd edn, 2006.

4 Y. Q. Fang, N. J. Taylor, F. Laverdière, G. S. Hanan, F. Loiseau, F. Nastasi, S. Campagna, H. Nierengarten, E. Leize Wagner and A. Van Dorsselaer, Inorg. Chem., 2007, 46, 28542863.

5 R. Passalacqua, F. Loiseau, S. Campagna, Y. Q. Fang and G. S. Hanan, Angew. Chem., Int. Ed., 2003, 42, 16081611.

6 D. G. Brown, N. Sanguantrakun, B. Schulze, U. S. Schubert and C. P. Berlinguette, J. Am. Chem. Soc., 2012, 134, 1235412357.

7 M. Abrahamsson, M. Jager, R. J. Kumar, T. Osterman, P. Persson, H. C. Becker, O. Johansson and L. Hammarstrom, J. Am. Chem. Soc., 2008, 130, 1553315542.

8 (a) W. E. Ford and M. A. J. Rodgers, J. Phys. Chem., 1992, 96, 2917 2920; (b) N. D. McClenaghan, F. Barigelletti, B. Maubert and S. Campagna, Chem. Commun., 2002, 602 603; (c) X. Y. Wang, A. Del Guerzo and R. H. Schmehl, J. Photochem. Photobiol., C, 2004, 5, 55 77; (d) N. D. McClenaghan, Y. Leydet, B. Maubert, M. T. Indelli and S. Campagna, Coord. Chem. Rev., 2005, 249, 1336 1350; (e) A. Lavie Cambot, C. Lincheneau, M. Cantuel, Y. Leydet and N. D. McClenaghan, Chem. Soc. Rev., 2010, 39, 506 515; $(f)$ D. S. Tyson and F. N. Castellano, J. Phys. Chem. A, 1999, 103, 10955 10960; $(g)$ M. Hissler, A. Harriman, A. Khatyr and R. Ziessel, Chem. Eur. J., 1999, 5, 3366 3381; (h) J. A. Simon, S. L. Curry, R. H. Schmehl, T. R. Schatz, P. Piotrowiak, X. Jin and R. P. Thummel, J. Am. Chem. Soc., 1997, 119, 11012 11022; (i) G. J. Wilson, A. Launikonis, W. H. F. Sasse and A. W. H. Mau, J. Phys. Chem. $A$, 1998, 102, 5150 5156; ( $j$ ) Y. Leydet, F. J. Romero Salguero, C. Jiménez Sanchidrián, D. M. Bassani and N. D. McClenaghan, Inorg. Chim. Acta, 2007, 360, 987 994; (k) L. Scarpantonio, A. Tron, C. Destribats, P. Godard and N. D. McClenaghan, Chem. Commun., 2012, 48, 39813983.

9 M. Jäger, L. Eriksson, J. Bergquist and O. Johansson, J. Org. Chem., 2007, 72, 1022710230

10 G. Chelucci, Tetrahedron Lett., 2010, 51, 15621565.

11 M. Jaeger, R. J. Kumar, H. Goerls, J. Bergquist and O. Johansson, Inorg. Chem., 2009, 48, 32283238. 